\title{
MANAGEMENT OF THE FLIGHT TRANSPORT AIRCRAFT DEPENDING ON THE FLIGHT LEVEL
}

\author{
Vladimir Grujić \\ Visoka poslovna škola strukovnih studija „Čačak“, Beograd, Srbija \\ Dragan Lazić \\ Loran Aviator, Harwood Heights, IL, USA
}

(C) MESTE NGO

JEL Category: M11, M29

\section{Apstrakt}

Osim u nekoliko poslednjih meseci 2014. godine, svet se od osamdesetih godina dvadesetog veka nalazi u konstantnoj krizi sa energentima, cija je direktna posledica stalan porast cene nafte na svetskom tržištu. To je primoralo mnoge proizvođače aviona da krenu u razvoj potpuno novih koncepata razvoja komercijalnih aviona koji će po potrošnji goriva biti mnogo racionalniji uz potpuno zadržavanje najvišeg nivoa usluge putnika. Neprekidan uzlazni trend cena goriva na svetskom tržištu u zadnjih tridesetak godina, primorao je ne samo manje kompanije već i najmoćnije firme u oblasti avio industrije, kao što je jedan „General Electric",da se vrate programima istraživanja i razvoja turbo-elisnih motora.

U slučaju aviona DHC Dash 8 Q 400 izvršeni su proračuni za promenu putnog goriva sa promenom nivoa leta. Izvršena je inženjerska priprema leta za proračun putnog goriva sa promenom nivoa leta od FL160 do FL240 (Nivo leta FL je površina konstantnog atmosferskog pritiska npr. $10000 \mathrm{ft}=\mathrm{FL} 100$ ). Aerodrom poletanja je na visini $P A=3000 \mathrm{ft}$, a aerodrom opredeljenja je na visini $P A=2000 \mathrm{ft}$. Na osnovu analize devet različitih nivoa leta neosporno se došlo do zaključka da bez obzira na veću visinu leta $i$ veću pređenu horizontalnu distancu u penjanju i spustanju utrošak goriva je znatno manji nego da se letelo na mnogo manjoj visini sa mnogo manjom horizontalnom distancom u penjanju i spuštanju. Svi pokazatelji do kojih se došlo nepobitno potvrđuju činjenicu da let na većoj visini omogućuje manji utrošak goriva i manje potrebno vreme leta.
\end{abstract}

Ključne reči: Nivo leta, penjanje, spuštanje, potrebno putno gorivo, vreme leta, menadžment, organizacija.

\section{Abstract \\ Adresa autora zaduženog za korespodenciju: Vladimir Grujić \\ 莑三” vladimir.grujic59@yahoo.com}

Except for the last few months of 2014, the world of the eighties of the twentieth century is in constant crisis of energy, which is a direct consequence of the steady increase in oil prices on the world market. It has forced many 
companies to develop new concepts of commercial aircraft to keep the highest level of passenger service by the lowest fuel consumption it shows much more cost-effective maintaining. Steady upward trend in fuel prices on the world market in the last thirty years, has forced not only small companies but also the most powerful company in the aerospace industry, such as a "General Electric", to return to research and development programs of turbo-propeller engines.

In the case of aircraft DHC Dash 8 Q 400 were calculated for the change of trip fuel with changing flight levels. Completed the engineering flight preparation for the calculation of trip fuel with changing flight levels from FL160 to FL240 (flight level FL is a surface of constant atmospheric pressure e.g. $10000 \mathrm{ft}$ $=$ FL100). The airport take-off at an altitude $P A=3000 \mathrm{ft}$, and the arrival airport is at an altitude $P A=2000 \mathrm{ft}$. Based on the analysis of nine different flight levels undoubtedly come to the conclusion that regardless of the higher altitude and greater horizontal distance traveled in climbing fuel consumption is significantly lower than that flew at a much lower altitude with a much smaller horizontal distance in climbing. All the indicators that were obtained conclusively confirm the fact that the flight at high altitude allows lower fuel consumption and less time needed for the flight.

Keywords: Flight level, climb, descent, required flight fuel, flight time, management, organization.

\section{UVOD}

Svet se od osamdesetih godina dvadesetog veka nalazi u konstantnoj krizi sa energentima koji se prvenstveno povezuju za stalan porast cene nafte na svetskom tržištu. (Lazic, 2013) To je primoralo mnoge proizvođače aviona da krenu u razvoj potpuno novih koncepata razvoja komercijalnih aviona koji će po potrošnji goriva biti mnogo racionalniji uz potpuno zadržavanje najvišeg nivoa usluge putnika. Sadašnja situacija sa cenom goriva na svetskom tržištu je takva da se čak i najmoćnije firme u oblasti avio industrije kao "General Electric", odluče da se vrate programima istraživanja i razvoja turbo-elisnih aviona. (Isaković, 2008)

Predsednik GE za infrastrukturni razvoj, John Rice, je potvrdio da će se raditi na razvoju nove generacije turbo-prop motora koji će odgovoriti zahtevima proizvođača novije generacije ovih vazduhoplova koji osim racionalnosti $u$ eksploataciji moraju da zadovolje i prohteve kao što su: povećani radijus rada, veća operativna visina leta, ali i smanjenje buke, pre svega u putničkoj kabini. Strateški partner u razvoju projekta novog motora nađen je u Češkoj, to jest tačnije u proizvođaču motora "Walter Engines". Čime će rezultovati ova saradnja, nije teško zaključiti. (Isakovic, 2006)

Prava jagma za turbo-elisnim motorima koja sada vlada širom sveta će se teško prevazići u dogledno vreme, barem dok se ne učine krupnije investicije u segmentu razvoja eliso-mlazne tehnologije. Potez "General Electric-a" i njihova integracija sa "Walter Engines" jasno govori da će se u doglednoj budućnosti pojaviti motor koji će omogućiti razvoj većih tubo prop letelica i to $u$ kategoriji do 90 putnika, što je i projektovani optimum za regionalni saobraćaj. (Isakovic, 2006)

Upravo iz ovih razloga u ovom radu će biti izvršeni proračuni utroška goriva za avion DHC Dash $8 \mathrm{Q}$ 400 koji je tipičan predstavnik turbo-elisnih aviona u regionalnom saobraćaju novije generacije. Proračuni će se izvršiti u okviru šire pretpostavljene envelope leta, analizirajući sve predviđene parametre leta.

\section{ANALIZA UTICAJA NIVOA LETA NA POTREBNO PUTNO GORIVO I VREME}

Glavna odrednica energetske potrošnje aviona je otpor, kojem se mora suprotstaviti potisak kako bi avion ostvario progresivan let. Otpor je srazmeran uzgonu potrebnom za održavanje visine koji je jednak težini aviona. Kako se indukovani otpor povećava $s$ težinom; smanjenjem mase, poboljšanjem efikasnosti motora i smanjenjem aerodinamičnog otpora može se znatno povećati energetska efikasnost aviona, što bi otprilike bilo jednako do $1 \%$ smanjenju težine, odnosno oko $0,75 \%$ smanjenju potrošnje goriva. (Swatton, 2008)

Teorija nedvosmisleno pokazuje da nadmorska visina leta utiče na opštu efikasnost motora. $U$ suštini efikasnost mlaznog motora povećava se povećanjem visine leta sve do tropo pauze gde je temperatura atmosfere najniža zbog niskih temperatura. $U$ tom smislu poredeći sa rezultatima empirijskih istraživanja efikasnost mlaznog motora 
veća je i s povećanjem brzine sve do oko 0,85 M usled čega se gubici radi aerodinamičke strukture vazduhoplova brže povećavaju. Ova vrednost Mahovog broja je izuzetno značajna jer sa početkom nadzvučnih brzina koje se na određenim delovima aviona mogu pojaviti na brzini oko $0,85 \mathrm{M}$, udarni talasi vazduha stvaraju sve veći otpor. Iz tog razloga na nadzvučnom letu, teško je postići specifični odnos uzgon/otpor veći od 5 , na osnovu istraživanja, te se usled toga potrošnja goriva proporcionalno povećava.

Ako se izvrši direktno upoređenje turbo mlaznog sa mlaznim pogonom, uočava se da najveću efikasnost daje propfen pogon. Činjenica je da turbo motori sa propelerom imaju optimalnu brzinu oko $700 \mathrm{~km} / \mathrm{h}$ pri čemu je ova brzina manja od brzine mlaznih aviona koje koriste većina današnjih kompanija. (Spakovszky, 2009) Poznato je da smanjenje brzine smanjuje i otpor. $S$ učestalom sve višom cenom mlaznog goriva i naglaskom na motor / struktura efikasnost i za smanjenje emisije gasova u atmosferu, obnovljen je interes za propfen koncept za putničke regionalne avione.

$\mathrm{U}$ daljem radu biće analiziran uticaj nivoa leta na potrebno putno gorivo i vreme turbo prop aviona De Havilland Canada DHC Dash 8 Q 400.

\subsection{Proračun putnog goriva vremena po EASA EU-OPS 1}

Gorivo potrebno za let deli se na putno gorivo koje se utroši od momenta startovanja motora na aerodromu poletanja do momenta gašenja motora na aerodromu opredeljenja i na rezervno gorivo koje se koristi za let do alternativnog aerodroma, za holding i usled navigacionih grešaka. Ukupno blok gorivo potrebno za realizaciju leta, predstavlja funkcionalnu zavisnost doleta, tj. sa povećanjem doleta linearno se povećava i količina potrebnog putnog goriva. U ovom radu biće razmotrena analiza uticaja nivoa leta na potrebno putno gorivo i vreme od FL160 do FL240 sa korakom 20. Takođe, proračun putnog goriva se ispituje za deo leta koji je „en route“, poletanje se izvodi sa RWY sa PA=3000 ft, a sletanje se izvodi na RWY sa $P A=2000 \mathrm{ft}$. Meteorološki uslovi na celom letu su: ISA+20, čeoni vetar $20 \mathrm{kt}$ (kt, čvor, je merna jedinica za brzinu $1,852 \mathrm{~km} / \mathrm{h}$ koja se koristi u vazduhoplovstvu i mornarici), bez turbulencije, bez uslova za zaleđivanje $\mathrm{i}$ bez značaja u varijaciji vlažnosti vazduha, svi motori su operativni. (Mirosavljevic, 2008)

\section{Proračun putnog goriva (Trip Fuel)}

Ova masa obuhvata gorivo potrebno za kompletno poletanje, penjanje, krstarenje i spuštanje, očekivane putne procedure i prilaz $\mathrm{i}$ sletanje na željenom aerodromu. Pre svakog leta izvodi se inženjerska priprema leta. Na osnovu podataka o pripremi leta predstavljenih $u$ Avionskom operativnom priručniku za avion DASH 8-400 dobijaju se sledeće vrednosti (Aircraft, 2006):

- Putno gorivo $=\mathbf{2} .606,00 \mathbf{~ k g}$;

- Putno vreme $=$ 2:46 (hr:min)

\section{Gorivo za nepredviđene slučajeve (Contingency Fuel)}

Ovo gorivo je namenjeno za nepredviđene slučajeve u toku leta ko što su: izbegavanje olujnog vremena i nepredviđeno dugo zadržavanje u prilazu za sletanje. Gorivo za nepredviđene slučajeve se obično određuje procentualno u odnosu na putno gorivo. Ne sme se zaboraviti da se ova masa goriva uračuna u sletnu masu aviona. Analogno tome dobija se vrednost (Series, 2009):

Gorivo za nepredviđene slučajeve (Contigency Fuel) $=$ Putno gorivo (Trip Fuel) $\times 5 \%$

- Gorivo za nepredviđene slučajeve $($ Contigency Fuel $)=2.606 \mathrm{~kg} \times 0,05=\mathbf{1 3 0 , 3 0} \mathbf{~ k g}$

\section{Alternativno gorivo (Alternate (Diversion) Fuel)}

Ova masa goriva se obezbeđuje za eventualnu promenu odredišnog aerodroma, sekvencijalno penjanje, produžene procedure prilaza za sletanje, navigacione greške $\mathrm{i} d r$. $U$ zadatom inženjerskom problemu nije uzet u obzir alternativni aerodrom.

\section{Krajnje rezerve goriva (Final Reserve Fuel)}

Ovo je minimalna količina-masa goriva koja ostaje u rezervoarima na sletanju. U osnovi krajnja rezerva goriva za nepredviđene eventualije treba približno da iznosi za klipno-elisne avione let od 45 minuta a za mlazne i turbo-elisne 30 minuta za datu visinu i prilaznu brzinu. Analogno tome dobijaju se vrednosti (Series, 2009): 
Krajnje rezerve goriva (Final Reserve Fuel) $=$ (Putno gorivo (Trip Fuel) / Putno vreme (Ttip Time)) $x$ 0:30

- Krajnje rezerve goriva (Final Reserve Fuel) $=$ $(2.606,00 \mathrm{~kg} / 2: 46$ (hr:min)) $\times 0: 30=$ $471,00 \mathrm{~kg}$

\section{Dodatno gorivo (Aditional Fuel)}

Ova količina goriva se planira samo ako suma količine goriva definisane u prethodnim stavkama je manja od zahteva definisanih u EASA EUOPS 1.

Dakle, ukupno putno gorivo i vreme potrebno za dati let iznosi:

Ukupno potrebno gorivo = Putno gorivo (Trip Fuel)

+ Gorivo za nepredviđene slučajeve (Contingency

Fuel)+

+ Krajnje rezerve goriva (Final Reserve Fuel)

- Ukupno potrebno gorivo na poletanju $=2.606$

$\mathrm{kg}+130,30 \mathrm{~kg}+471 \mathrm{~kg}=\mathbf{3 . 2 0 7 , 3} \mathbf{~ k g}$;

Maksimalno vreme trajanja leta $=3: 16$

(hr:min)

\subsection{Proračun mase aviona na poletanju}

$\mathrm{Na}$ osnovu vrednosti dobijene u tački 2.1 za ukupno potrebno gorivo za let i na osnovu ulaznih vrednosti za suvu operativnu masu aviona DOM i plaćeni teret (Traffic Load TL), proračunava se ukupna masa aviona na poletanju TOM, dobija se sledeće (Series, 2009):

Masa bez goriva $(Z F M)=D O M+T L$

- Masa bez goriva $(Z F M)=17.268,00 \mathrm{~kg}+$ $5.247,00 \mathrm{~kg}=\mathbf{2 2 . 5 1 5 , 0 0} \mathbf{~ k g}$

Sada je moguće proračunati ukupnu masu aviona na poletanju:

Masa na poletanju $($ TOM $)=Z F M+$ Fuel

- Masa na poletanju (TOM) $=22.515,00 \mathrm{~kg}+$ $3.207,3 \mathrm{~kg}=\mathbf{2 5 . 7 2 2 , 3 0} \mathbf{~ k g}$

\subsection{Analiza promene pređene} horizontalne distance potrebne za penjanje, krstarenje i poniranje s obzirom na promenu nivoa leta

Na osnovu prikazanih vrednosti u proračunu mase aviona na poletanju TOM iz tačke 2.2, dobijene vrednosti se koriste dalje u proračunima kako bi se dobile tražene vrednosti $u$ horizontalnoj distanci, potrebnom gorivu i vremenu za različize režime leta (penjanje, krstarenje i poniranje) za zadate nivoe leta. Za dalju analizu potrebno je utvrditi promene u horizontalnoj distanci za svaki od režima leta sa promenom visine od nivoa leta FL160 do FL240.

Koristeći Avionski operativni priručnik dobijamo sledeće vrednosti (Aircraft, 2006):

\section{Penjanje na FL160}

Vrednosti za proračun brzine u penjanju KIAS dobijaju se iz Avionskog operativnog priručnika. (Aircraft, 2006) Proračunata vrednost za FL160 je 205 KIAS. Ovim putem se dobijaju i vrednosti za ostale nivoe leta do FL240.

Tabela 1. Proračun brzine u penjanju KIAS od FL160 do FL240 (Gvozdenovic, 2011)

\begin{tabular}{|l|l|l|l|l|l|l|l|l|l|}
\hline FL & 160 & 170 & 180 & 190 & 200 & 210 & 220 & 230 & 240 \\
\hline KIAS & 205 & 200 & 195 & 190 & 185 & 180 & 175 & 170 & 165 \\
\hline
\end{tabular}

Prema podacima iz Tabele 1. uočava se pad brzine KIAS za vrednost od $5 \mathrm{kt}$ na svakih $1.000 \mathrm{ft}$ visine.

$\mathrm{Na}$ osnovu ulaznih parametara gde je: Type I tip penjanja, korak tokom celog leta 20 , približna vrednost mase aviona od 26 tona, avion poleće sa RWY sa PA $=3.000 \mathrm{ft} i$ penje na nivo FL160 (koristi se razlika FL160-FL30 za dobijanje vrednosti u tabeli), koristeći AOM dobijaju se sledeće vrednosti za horizontalnu distancu, vreme penjanja i potrebno gorivo:

- Horizontalna distanca: 30,5 Nm; Vreme penjanja: $9 \mathrm{~min}$;

Potrebno gorivo u penjanju: $\mathbf{2 3 4} \mathbf{~ k g}$.

Sada je moguće dobiti vrednosti za promene nivoa leta od FL160 do FL240 po istom principu.

Promenom visine za $1.000 \mathrm{ft}$ uočava se da vreme trajanja leta iznosi $1 \mathrm{~min}$ iz čega se dolazi do podatka da avion ima brzinu penjanja od $1.000 \mathrm{fpm}$, što prema AOM za ovaj avion vrednosti se poklapaju. Prema AOM, navodi se da na manjim visinama avion ima brzinu penjanja od 2500-3000 fpm, dok sa povećanjem visine, ta brzina opada. Takođe, uočava se zavisnost između promene visine i horizontalne distance sa potrošnjom goriva. 


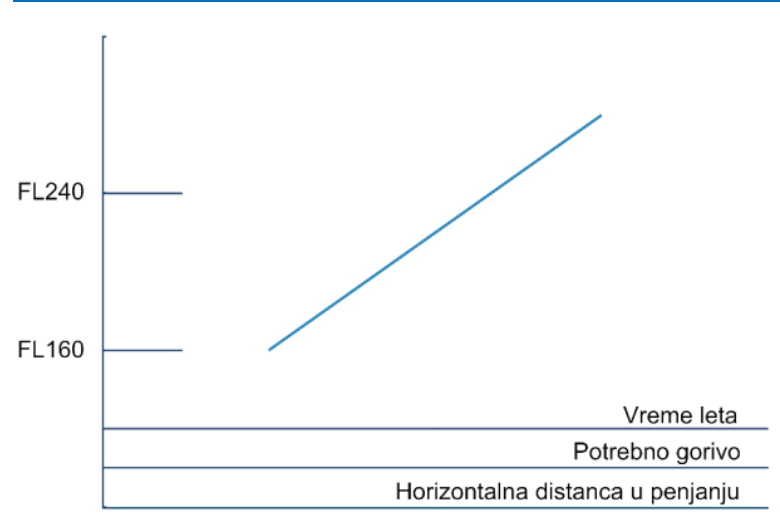

Slika 1. Zavisnost između rezultata, Nivoa leta sa potrebnim gorivom, vremenom i horizontalnom distancom u penjanju

Naime, na svakih $1.000 \mathrm{ft}$ promene visine, povećava se linearno i horizontalna distanca $u$ proseku za $4 \mathrm{Nm}$, a takođe i potrošnja goriva u proseku za $18 \mathrm{~kg}$. Ovakva zavisnost između rezultata se najbolje uočava na grafičkom prikazu na Slici 1.

\section{Poniranje sa FL160}

Vrednosti za proračun brzine u poniranju KIAS dobijaju se na osnovu AOM. (Aircraft, 2006) Proračunata vrednost za FL160 je 277 KIAS. Ovim putem se dobijaju i vrednosti za ostale nivoe leta do FL240.

\section{Tabela 2 Proračun brzine u poniranju KIAS od FL160 do FL240}

\begin{tabular}{|l|l|l|l|l|l|l|l|l|l|}
\hline FL & 160 & 170 & 180 & 190 & 200 & 210 & 220 & 230 & 240 \\
\hline KIAS & 277 & 277 & 277 & 268 & 260 & 250 & 247 & 243 & 240 \\
\hline
\end{tabular}

Prema dobijenim podacima iz Tabele 2. uočava se da sa promenom visine pada i brzina KIAS. Pad brzine nije linearnog karaktera, već je konstantan do nivoa leta FL180, a zatim eksponencijalno opada.

Na osnovu ulaznih parametara gde je: Type I tip poniranja, korak tokom celog leta 20 , približna vrednost mase aviona od 26 tona, avion sleće na RWY sa PA $=2.000 \mathrm{ft}$ sa nivoa FL160 (koristi se razlika FL160-FL20 za dobijanje vrednosti u tabeli), koristeći AOM, dobijaju se sledeće vrednosti za horizontalnu distancu, vreme penjanja i potrebno gorivo:

\section{- Horizontalna distanca: 34 Nm}

( $\mathrm{Nm}$ - nautička milja, $1 \mathrm{Nm}=1.852,00 \mathrm{~m}$ ),
- Vreme poniranja: 11 min;

Potrebno gorivo u poniranju: 129 kg.

Pošto se let odvija po meteorološkim uslovima gde je ISA +20 potrebno je izvršiti određene korekcije gde za ISA +20 su sledeći uslovi:

- Dodaje se 5\% na horizontalnu distancu; Dodaje se $6 \%$ na potrebno gorivo.

Nakon izvršene korekcije rezultati su sledeći:

- Horizontalna distanca: 36 Nm; Vreme poniranja: $11 \mathrm{~min}$;

Potrebno gorivo u poniranju: $137 \mathbf{~ k g}$.

Sada je moguće dobiti vrednosti za promene nivoa leta od FL160 do FL240 po istom principu. $\mathrm{Na}$ osnovu dobijenih podataka dobija se da promenom visine za $1.000 \mathrm{ft}$ potrebno je vreme od 2 min u proseku, iz čega se može izvesti zaključak da avion snižava brzinom od 500 fpm. Takođe, uočava se da sa porastom nivoa leta povećanje horizontalne distance $u$ poniranju nije linearnog karaktera, već na manjim visinama ima jednu linearnost od $3 \mathrm{Nm}$, dok iznad FL180 je to drugi oblik linearnost u proseku od $11 \mathrm{Nm}$ na svakih $1.000 \mathrm{ft}$ visine. Isto pravilo važi i za potrošnju goriva jer je ona direktno vezana za pređenu horizontalnu distancu.

\section{Krstarenje na FL160}

Koristeći AOM dobijaju se vrednosti u krstarenju za KIAS,KTAS i potrošnju goriva po času leta. Ove vrednosti za krstarenje na nivou leta FL160 su:

- KIAS: 211 kt; KTAS: 278 kt;

- Potrošnja goriva po času leta: 878 kg/h

Takođe, koristeći vrednosti iz AOM po istom principu dobija se zavisnost promene KIAS sa visinom leta, od FL160 do FL240. Ova zavisnost je prikazana u Tabeli 3.:

Tabela 3 Proračun brzina KIAS u krstarenju u zavisnosti sa promenom visine od FL160-FL240

\begin{tabular}{|l|l|l|l|l|l|l|l|l|l|}
\hline FL & 160 & 170 & 180 & 190 & 200 & 210 & 220 & 230 & 240 \\
\hline KIAS & 211 & 210 & 209 & 208 & 206 & 203 & 201 & 199 & 197 \\
\hline
\end{tabular}

$\mathrm{Na}$ osnovu podataka iz Tabele 3 . dolazi se do zaključka da sa povećanjem visine do FL180 brzina KIAS opada linearno za $1 \mathrm{kt}$ na svakih $1.000 \mathrm{ft}$, dok iznad FL180 linearnost ostaje, te na svakih $1.000 \mathrm{ft}$ visine brzina KIAS opada za $u$ proseku $2 \mathrm{kt}$. 
Pored podataka dobijenih za analizu KIAS sa promenom visine, značajni su i podaci za KTAS koji se menjaju takođe sa promenom visine. Od tih vrednosti zavisi putna brzina GS, koja se proračunava na osnovu vetra (čeoni vetar tokom celog leta od $20 \mathrm{kt}$ ) i KTAS. Putna brzina na nivou leta FL160 iznosi:

GS $=$ TAS +- Wind

- $\mathrm{GS}(160)=278 \mathrm{kt}-20 \mathrm{kt} ; \mathrm{GS}(160)=258 \mathrm{kt}$

Tabela 4. KTAS i GS vrednosti u krstarenju, prikazane u zavisnosti sa promenom nivoa leta od FL160-FL240

\begin{tabular}{|l|l|l|l|l|l|l|l|l|l|}
\hline FL & 160 & 170 & 180 & 190 & 200 & 210 & 220 & 230 & 240 \\
\hline KTAS & 278 & 281 & 284 & 286 & 289 & 291 & 292 & 294 & 296 \\
\hline GS & 258 & 261 & 264 & 266 & 269 & 271 & 272 & 274 & 276 \\
\hline
\end{tabular}

KTAS i GS vrednosti u zavisnosti od visine leta su prikazani u Tabeli 4.

Koristeći podatke iz Tabele 4. i vrednosti dobijene u penjanju i poniranju dobijamo sledeće:

Ukupna distanca $=$ Horizontalna distanca $u$
penjanju + Distanca u krstarenju +
Horizontalna distanca u poniranju (7)

- Distanca u krstarenju $(F L 160)=800 \mathrm{Nm}-$ $(30,5 \mathrm{Nm}+36 \mathrm{Nm})=\mathbf{7 3 3}, \mathbf{5} \mathrm{Nm}$

Koristeći jednačinu (7) dobijaju se i za ostale nivoe leta vrednosti distance u krstarenju.

\section{Tabela 5. Vrednosti horizontalne distance $u$ krstarenju, prikazane sa promenom nivoa leta od FL160-FL240}

\begin{tabular}{|l|l|l|l|l|l|l|l|l|l|}
\hline FL & 160 & 170 & 180 & 190 & 200 & 210 & 220 & 230 & 240 \\
\hline Hor.dist. & 733,5 & 727 & 718 & 704 & 688,5 & 672 & 656 & 641 & 627 \\
\hline
\end{tabular}

$\mathrm{Na}$ osnovu Tabele 5. uočava se razlika $u$ horizontalnim distancama u krstarenju sa promenom visine. Razlika sa visinom opada linearno sa manjom razlikom do nivoa leta FL180, a iznad te visine uočava se razlika u proseku od $16 \mathrm{Nm}$ sa promenom visine od $1.000 \mathrm{ft}$.

Koristeći vrednosti dobijene u jednačinama (6) i (7) i kasnije Tabele 4. i 5. dobija se vreme leta $u$ krstarenju:
Vreme leta u krstarenju = Horizontalna distanca / Putna brzina

- Vreme leta u krstarenju (FL160) =733,5 Nm / $258 \mathrm{Nm} / \mathrm{hr}=\mathbf{2 , 8 4} \mathrm{hr}-->171,5 \mathrm{~min}$

Koristeći jednačinu (8) dobijaju se i za ostale nivoe leta vrednosti potrebnog vremena u krstarenju.

Radi detaljne analize vremena tokom leta sa promenom visine vrednosti dobijene u Tabelama 4,5 . i jednaćini (8) iskoristiće se u jednačini (9):

Ukupno vreme leta $=$ Vreme penjanja + Vreme krstarenja + Vreme poniranja

- Ukupno vreme leta $(F L 160)=9 \mathrm{~min}+11 \mathrm{~min}$ $+171,5 \mathrm{~min}=\mathbf{1 9 1 , 5} \mathrm{min}-->\mathbf{3 , 1 7} \mathrm{hr}$

Koristeći jednačinu (9) dobijaju se i za ostale nivoe leta vrednosti potrebnog vremena u krstarenju.

Tabela 6. Ukupno vreme trajanja leta, prikazano sa pomenom nivoa leta od FL160-FL240

\begin{tabular}{|l|l|l|l|l|l|l|l|l|l|}
\hline FL & 160 & 170 & 180 & 190 & 200 & 210 & 220 & 230 & 240 \\
\hline $\begin{array}{l}\text { Vreme } \\
\text { [hr] }\end{array}$ & 3,17 & 3,14 & 3,10 & 3,08 & 3,04 & 3,01 & 2,99 & 2,96 & 2,94 \\
\hline
\end{tabular}

$\mathrm{Na}$ osnovu Tabele 6. uočava se da se sa povećanjem visine smanjuje vreme trajanja leta. Takođe, na osnovu analize vremena potrebnog za let uočava se da vreme penjanja i poniranja je značajno veće za veće nivoe leta, vreme je direktno povezano sa utrošenom energijom da avion dobije i izgubi visinu. Značajan je i podatak da su horizontalne distance u krstarenju značajno kraće na višim nivoima, jer tokom penjanja i poniranja potrebna je veće horizontalna distanca za više nivoe leta, a da to vreme u penjanju i poniranju nije uticalo da ukupno vreme trajanja leta na većim nivoima leta bude kraće.

Za definisanje potrebne količine goriva $u$ krstarenju koriste se vrednosti iz AOM i vrednosti dobijene u Tabeli 6:

Količina goriva u krstarenju = Potrošnja goriva po času leta $x$ Vreme trajanja leta

- Količina goriva u krstarenju (FL160) = $878 \mathrm{~kg} / \mathrm{h} \times 2,84 \mathrm{hr}=\mathbf{2 . 4 9 3 , 5} \mathbf{~ k g}$

Koristeći jednačinu (10) dobijaju se i za ostale nivoe leta vrednosti potrebne količine goriva $u$ krstarenju. 
Radi detaljne analize ukupne količine goriva potrebne tokom leta sa promenom visine vrednosti dobijene $u$ ranijim proračunima iskoristiće se u jednačini (11):

Ukupna kol. goriva $=$ Kol. goriva u penjanju + Kol. goriva u krstarenju + Kol. goriva u poniranju (11)
- Ukupna kol. goriva $(F L 160)=234 \mathrm{~kg}+$ $2.493,5 \mathrm{~kg}+137 \mathrm{~kg}=\mathbf{2 . 8 6 4 , 5} \mathbf{~ k g}$

Koristeći jednačinu (11) dobijaju se i za ostale nivoe leta vrednosti ukupne količine goriva prikazane u tabeli 7 .

Tabela 7 Vrednosti ukupne količine goriva prikazane sa promenom nivoa leta od FL160-FL240

\begin{tabular}{|c|c|c|c|c|c|c|c|c|c|}
\hline $\mathrm{FL}$ & 160 & 170 & 180 & 190 & 200 & 210 & 220 & 230 & 240 \\
\hline $\mathrm{kg}$ & $2.864,5$ & $2.806,2$ & $2.750,3$ & $2.710,2$ & $2.673,7$ & $2.650,9$ & $2.644,1$ & $2.611,7$ & $2.587,3$ \\
\hline
\end{tabular}

$\mathrm{Na}$ osnovu Tabele 7 uočava se da se sa povećanjem visine smanjuje ukupna količina goriva. Takođe, na osnovu analize goriva potrebnog za let uočava se da gorivo potrebno za penjanje i poniranje je značajno veće za veće nivoe leta, gorivo je direktno povezano sa utrošenom energijom da avion dobije $\mathrm{i}$ izgubi visinu. Značajan je i podatak da je u krstarenju potrebna značajno manja količina goriva na višim nivoima. Sumirano, iako je veća količina goriva potrebna tokom penjanja i poniranja za više nivoe leta, to ne utiče na promenu da ukupna količina goriva na višim nivoima leta bude znatno manja nego na nižim nivoima leta.

\section{ZAKLJUČAK}

Na osnovu izvedenih proračuna Poglavlju 2.3, dobijeni podaci pokazuju da poredeći performanse aviona DHC 8 Dash 8 Q 400 na različitim nivoima leta, da je ekonomski (po pitanju količine potrebnog putnog goriva) a i po pitanju vremena bolje odabrati nivoe leta na većoj visini nego na manjoj. Rezultati pokazuju da u slučaju istog ugla penjanja i poniranja za svaki nivo leta, bez obzira što će se horizontalna distanca povećavati proporcionalno povećanju nivoa leta, znatno je manja potrošnja u ukupnoj količini goriva i potrebnog putnog vremena za let nego na nižim nivoima leta.

Problemi sa energentima i saznanje da su naftni resursi vrlo ograničeni, a da se uz to nije došlo do otkrivanja novih vrsta goriva, prilikom ulaska u novi milenijum mnoge avio kompanije na bazi proračuna-planiranja putnog goriva došle su do zaključka da u regionalnom avio saobraćaju nije rentabilna primena mlaznih putničkih aviona. Odnos cene karte za neku destinaciju i mogući ostvareni profit, koji je vrlo često bio ispod granice rentabilnosti, kod mlaznih putničkih aviona pokazao je da u slučaju turbo elisnih aviona koji su prilagođeni regionalnom saobraćaju, daje daleko bolje rezultate i kompanija može da računa na sticanje profita zahvaljujući boljim letnim performansama a to se posebno odnosi na potrošnju goriva.

Značaj zaključaka do kojih se dolazi inženjerskim proračunom potrošnje putnog goriva sa promenom nivoa leta potvrđuju objavljeni podaci avio kompanije Malezia Airlines koja je u maju 2013. godine sklopila ugovor vredan tri milijarde dolara za kupovinu 36 ATR 72-600 najnovijeg modela tog proizvođača na konto toga što su u poslednjem kvartalu 2012. godine iskazali pad profita jer su se za regionalni saobraćaj koristili mlazni putnički avioni, dok su nasuprot tome u floti imali i 12 ATR 72-500 koji su u regionalnom saobraćaju obezbedili porast profita kompaniji u istom periodu. Na bazi svega prethodno iznetog može se zaključiti da će budućnost regionalnog saobraćaja biti u turbo-propelerskim motorima zbog manjeg utroška goriva, ali i racionalnijih svih drugih parametara koji se kroz profit kompanije na kraju iskazuju.

\section{Citirani radovi}

Aircraft, B. A. (2006). Aircraft Operational Manual Dash 8 Q 400. Bombardier.

Gvozdenovic, S. (2011). Performanse transportnih vazduhoplova, Univerzitet u Beogradu. Beograd: Saobracajni fakultete Univerziteta u Beogradu. 
Isakovic, V. (2006). Veliki povratak turbo-prop tehnologije. Udruženje linijskih pilota Srbije, Jun.

Isaković, V. (2008, 06 26). Veliki povratak turbo-prop tehnologije. Retrieved from Udruženje linijskih pilota Srbije: http://www.udruzenjepilota.org/arhiva/08/06/080626ge.htm

Lazic, D. (2013). Analiza uticaja nivoa leta na potrebno putno gorivo i vreme transportnog aviona performansi klase A. Beograd.

Mirosavljevic, P. (2008). Upravljacke aktivnosti vazduhoplovnih kompanija u cilju smanjenja potrošnje goriva. SYM-OP-IS.

Series, A. G. (2009). Flight Performance and Planning 1, Mass and Balance. London: Oxford Aviation Academy.

Spakovszky, Z. (2009, 04 03). Unified Propulsion Lecture 1. Récupéré sur Unified Engineering Lecture Notes.

MIT: http://web.mit.edu/16.unified/www/SPRING/propulsion/UnifiedPropulsion3/UnifiedPropulsion3. $\mathrm{htm}$

Swatton, P. (2008). Aircraft Performance Theory and Practice for Pilots. New York: John Wiley \& Sons Ltd.

Datum prve prijave:

17.11 .2014

Datum prijema korigovanog članka:

24.12.2014

Datum prihvatanja članka:

26.12.2014

\section{Kako citirati ovaj rad? / How to cite this article?}

Style - APA Sixth Edition:

Grujić, V., \& Lazić, D. (2015, Jan 15). Menadžment organizacije leta putničkog aviona u zavisnosti od nivoa leta. (Z. Čekerevac, Ed.) FBIM Transactions, 3(1), 130-138. doi:10.12709/fbim.03.03.01.15

Style - Chicago Sixteenth Edition:

Grujić, Vladimir, and Dragan Lazić. 2015. "Menadžment organizacije leta putničkog aviona u zavisnosti od nivoa leta." Edited by Zoran Čekerevac. FBIM Transactions (MESTE) 3 (1): 130-138. doi:10.12709/fbim.03.03.01.15.

Style - GOST Name Sort:

Grujić Vladimir and Lazić Dragan Menadžment organizacije leta putničkog aviona u zavisnosti od nivoa leta [Journal] // FBIM Transactions / ed. Čekerevac Zoran. - Beograd : MESTE, Jan 15, 2015. 1 : Vol. 3. - pp. 130-138.

Style - Harvard Anglia:

Grujić, V. \& Lazić, D., 2015. Menadžment organizacije leta putničkog aviona u zavisnosti od nivoa leta. FBIM Transactions, 15 Jan, 3(1), pp. 130-138.

Style - ISO 690 Numerical Reference:

Menadžment organizacije leta putničkog aviona u zavisnosti od nivoa leta. Grujić, Vladimir and Lazić, Dragan. 2015. [ed.] Zoran Čekerevac. 1, Beograd: MESTE, Jan 15, 2015, FBIM Transactions, Vol. 3, pp. 130-138. 


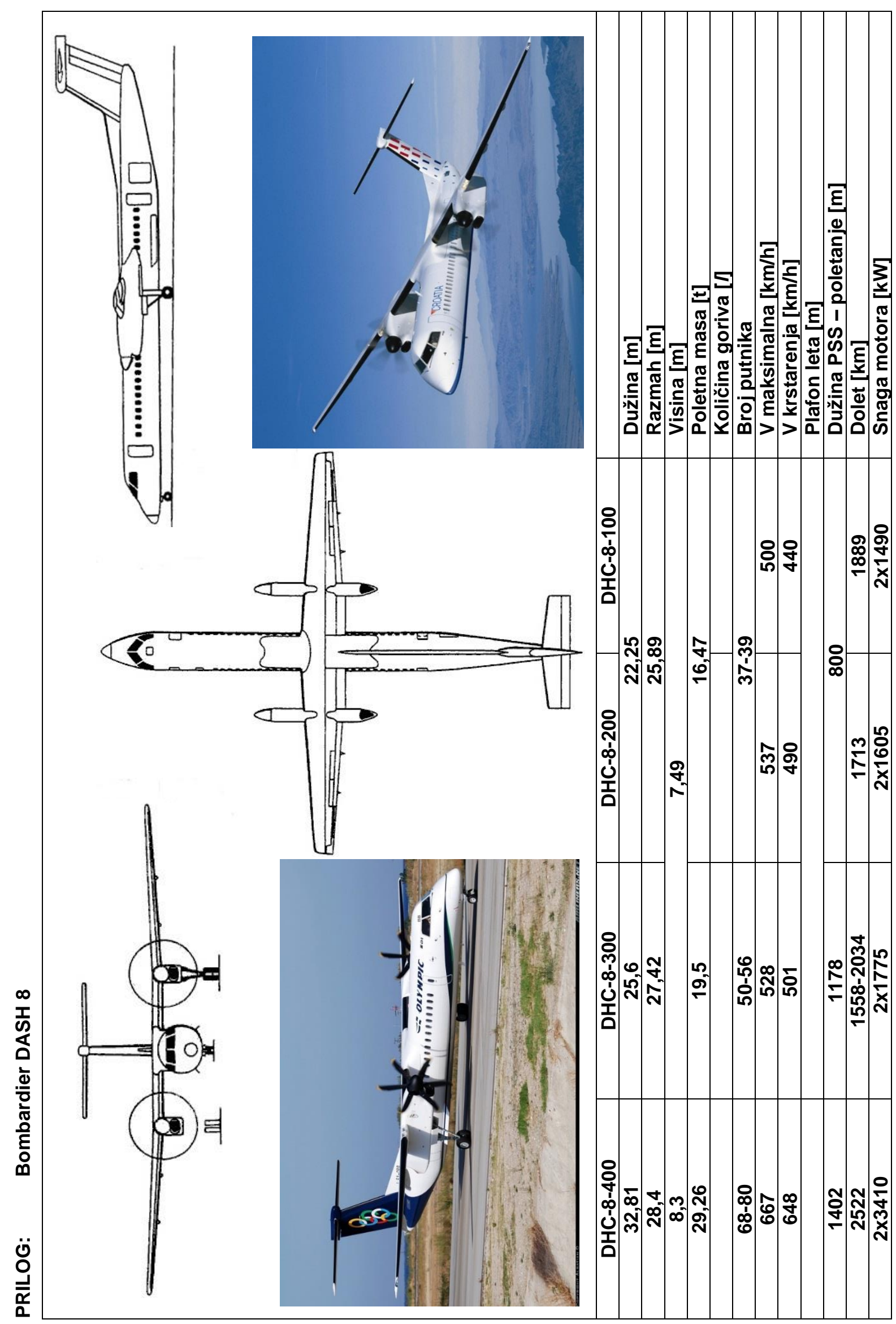

